\title{
Gold-Catalyzed Growth of Aluminium-Doped Zinc Oxide Nanorods by Sputtering Method
}

\author{
A. B. Rosli, ${ }^{1}$ M. M. Marbie, ${ }^{1}$ S. H. Herman, ${ }^{1,2}$ and M. H. Ani ${ }^{3}$ \\ ${ }^{1}$ NANO-Electronic Center, Faculty of Electrical Engineering, Universiti Teknologi MARA, 40450 Shah Alam, Selangor, Malaysia \\ ${ }^{2}$ CoRe of Frontier Materials \& Industry Applications, Universiti Teknologi MARA, 40450 Shah Alam, Selangor Darul Ehsan, Malaysia \\ ${ }^{3}$ Kulliyyah of Engineering, International Islamic University Malaysia, P.O. Box 10, 50728 Kuala Lumpur, Malaysia
}

Correspondence should be addressed to A. B. Rosli; aimi_bazilah@hotmail.com

Received 23 April 2014; Revised 3 July 2014; Accepted 3 July 2014; Published 17 July 2014

Academic Editor: Margarida Amaral

Copyright (C) 2014 A. B. Rosli et al. This is an open access article distributed under the Creative Commons Attribution License, which permits unrestricted use, distribution, and reproduction in any medium, provided the original work is properly cited.

\begin{abstract}
Aluminium-doped zinc oxide (AZO) nanorods thin films were grown by RF magnetron sputtering on gold (Au) metal catalyst. The Au catalyst layers with 5,10 , and $15 \mathrm{~nm}$ thickness were deposited on glass substrates by sputtering method followed by annealing for $15 \mathrm{~min}$ at $500^{\circ} \mathrm{C}$ to form Au nanostructures on the glass substrate. The AZO thin films were then deposited on the Au catalyst at different deposition temperature varying from 200 to $500^{\circ} \mathrm{C}$. Postdeposition annealing processes of the Au catalyst resulted in different morphologies of the Au catalyst layers depending on their thicknesses. This in turn gave different AZO morphologies which suggest that the Au catalyst layer thickness and the deposition temperature contribute to the growth mechanism of the AZO nanostructures. AZO nanorods thin films having hexagonal wurtzite structure with individual nanorods on the film surface were obtained from the samples deposited on 5 and $10 \mathrm{~nm}$ thick Au catalyst with the deposition temperature of $300^{\circ} \mathrm{C}$.
\end{abstract}

\section{Introduction}

Transparent conductive oxide (TCO) films have been extensively studied on a broad range of applications due to their low resistivity and high transmittance of visible light [1]. Among the various TCO films, aluminium-doped zinc oxide (AZO) is one of the promising materials for industrial use due to its advantages such as low cost and nontoxicity as well as exhibiting good stability in hydrogen plasma [1-4]. There are various techniques to deposit AZO nanorods thin films such as sol-gel [5], plasma enhanced chemical vapour deposition (CVD) [6], and RF-sputtering [7]. Of all mentioned deposition techniques, the RF magnetron sputtering is the least investigated for the fabrication of $1 \mathrm{D}$ nanostructures whereas it is most widely used to deposit uniform thin film [8]. To allow compatibility of nanorods growth with the matured CMOS manufacturing technology, we therefore explored the growth of nanorods by sputtering method. In this work, the AZO nanostructures were deposited using RF-sputtering method assisted by gold $\mathrm{Au}$ ) catalyst due to a large number of reports of Au-catalyst assisted growth of nanorods by CVD methods [9-11] although the reports on sputtering are limited. The thickness of the Au catalyst layer was varied from 5 to $15 \mathrm{~nm}$, and, for comparison, deposition on bare glass was also carried out. The deposition temperatures were varied from 200 to $500^{\circ} \mathrm{C}$, which are relatively lower compared to other reported growth temperatures [12].

\section{Experimental}

In this research, Au catalyst was used to initiate and enhance the nanorods growth. Au catalyst layers with 5, 10, and $15 \mathrm{~nm}$ thickness were deposited on glass substrates by a sputter coater. Prior to Au catalyst deposition process, the substrates were subjected to cleaning process in ultrasonic bath for $10 \mathrm{~min}$ at $50^{\circ} \mathrm{C}$ using acetone, methanol, and deionized water (DIW) in sequence to ensure that the substrates are free from dirt and contamination. Then the deposited Au layers were annealed at $500^{\circ} \mathrm{C}$ in a furnace for $15 \mathrm{~min}$ in ambient air. The AZO thin films were then deposited on the Au catalyst layer by radio frequency (RF) magnetron sputtering which used high purity ceramic target with $98 \%$ of $\mathrm{ZnO}$ doped with $2 \%$ of $\mathrm{Al}_{2} \mathrm{O}_{3}$. RF power of $200 \mathrm{~W}$ was used throughout 


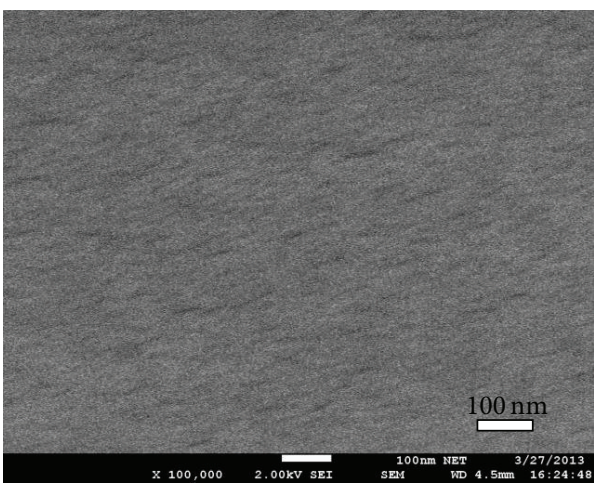

(a)

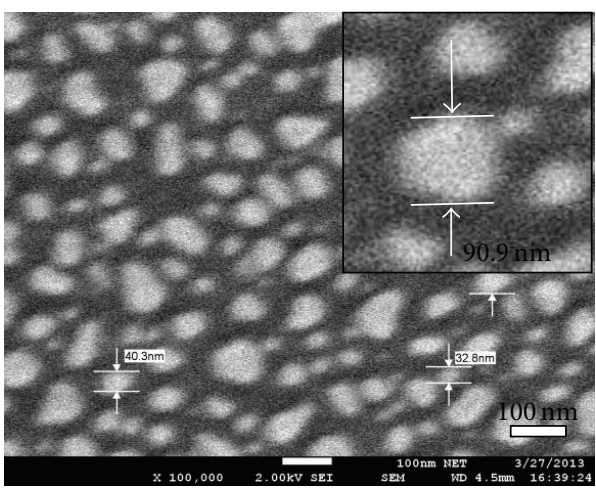

(c)

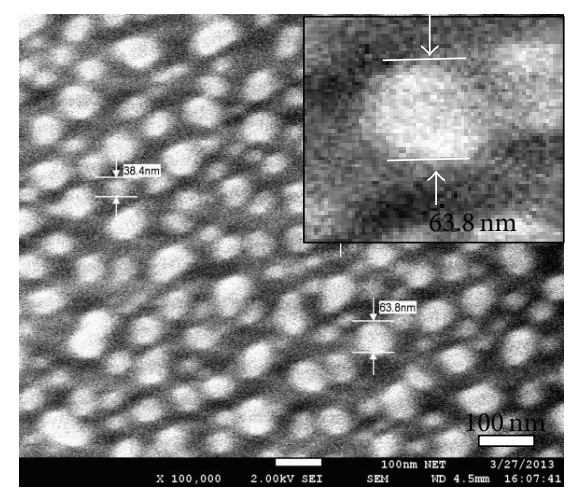

(b)

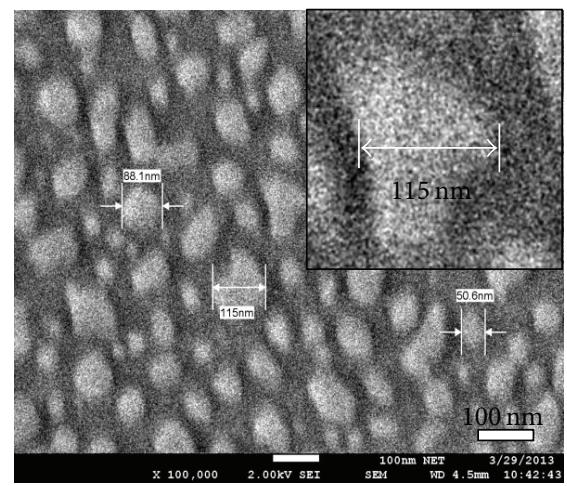

(d)

FIGURE 1: FESEM images of (a) Au catalyst thin film before annealing and (b) 5, (c) 10, and (d) $15 \mathrm{~nm}$ thicknesses of Au catalyst morphologies after annealing in ambient air at $500^{\circ} \mathrm{C}$ and each inset in (a), (b), and (c) shows the enlarged view.

the process and pressure inside the chamber was $0.5 \mathrm{~Pa}$. The deposition temperatures during sputter were varied from 200 to $500^{\circ} \mathrm{C}$. The argon (Ar) gas was used as the sputtering gas with the flow rate set to $20 \mathrm{sccm}$. A presputtering time of $10 \mathrm{~min}$ was used in order to ensure the stabilization of sputtering conditions.

Field effect scanning electron microscope (FESEM, JEOL JSM 7600F) was used to observe the surface morphology and cross-section of the AZO nanostructures while energy dispersive X-ray spectroscopy (EDX) is used to determine the elemental compositions of AZO thin films. The crystal structure of the films was analyzed by using X-ray diffractometer (XRD, Rigaku Ultima IV with a $\mathrm{Cu} \mathrm{K} \alpha$ ), in which $\lambda=0.15406 \mathrm{~nm}$, and also Raman spectroscopy.

\section{Results and Discussion}

3.1. Effect of Au Catalyst Thickness. Figure 1(a) shows the $\mathrm{Au}$ catalyst layer morphology before annealing and Figures 1(b)1 (d) show those after annealing for $15 \mathrm{~min}$ in ambient air for the thickness of 5, 10, and $15 \mathrm{~nm}$, respectively. The Au layer for nonannealed sample was dense and continuous. We can see that the annealing process restructured the Au layer and formed island morphologies with different sizes. From the inset, it can be seen that the Au particles sizes were increased from $63.8 \mathrm{~nm}$ to $115 \mathrm{~nm}$ when the thickness of Au layer was increased from $5 \mathrm{~nm}$ to $15 \mathrm{~nm}$, respectively, suggesting that the layer thickness influenced the size of the particle.

Figures 2(a), 2(b), 2(c), and 2(d) show the AZO nanostructures grown on bare glass and also on 5, 10, and $15 \mathrm{~nm}$ thick Au catalysts deposited at $300^{\circ} \mathrm{C}$, respectively. From Figure 2(a), it can be seen that a dense and continuous AZO thin film is grown on the bare glass without any formation of nanostructures. On the other hand, unoriented individual AZO nanorods can be seen on the sample surface which was deposited on the $5 \mathrm{~nm}$ Au catalyst as shown in Figure 2(b). However, the AZO nanorods density decreases when the $\mathrm{Au}$ catalyst thickness was increased to 10 and $15 \mathrm{~nm}$, respectively. Comparing the thin films on glass and on $5 \mathrm{~nm}$ Au catalyst, it can be said that the Au catalyst facilitates the nucleation sites for the AZO nanorods growth on the $5 \mathrm{~nm}$ sample.

The FESEM cross-section images of the samples shown in Figures 3(a), 3(b), 3(c), and 3(d) clearly exhibit the columnar growth of the AZO nanorods thin films, especially for the films grown on the 5 and $10 \mathrm{~nm}$ Au catalyst layers. We can see that the film grown on the bare substrate is dense proving the role of the Au catalyst layer on the formation of the nanorods. The thicknesses of the AZO thin films from the cross-section are $602,578,641$, and $683 \mathrm{~nm}$, respectively. It can be said that increasing the Au catalyst thickness from 5 to $15 \mathrm{~nm}$ will cause the AZO thin films to increase. This effect is due to the surface diffusion that caused the deposited particles to stack and rearrange [13]. These columnar structures are also reported 


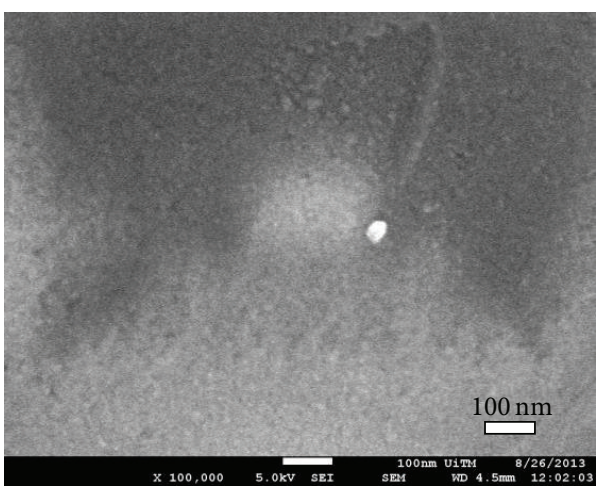

(a)

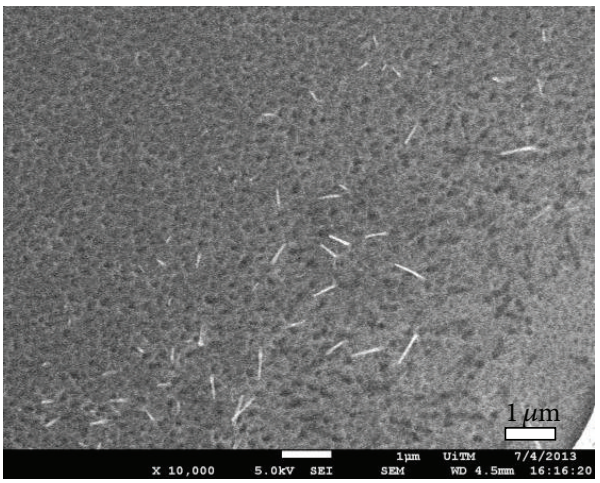

(c)

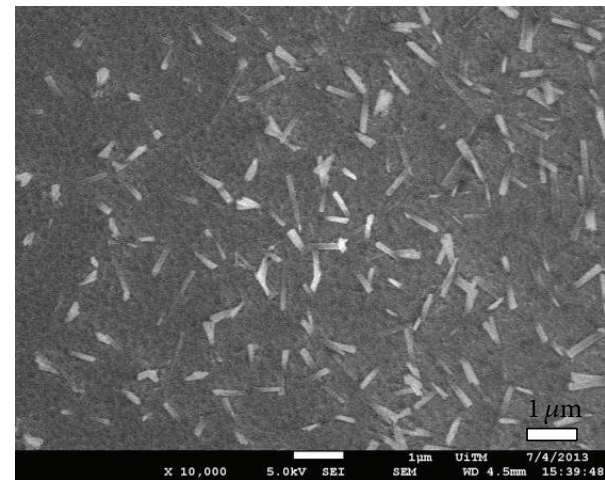

(b)

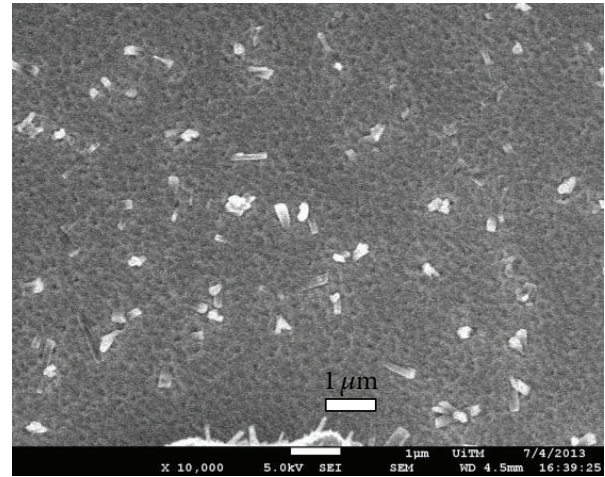

(d)

FIGURE 2: FESEM surface morphology of AZO nanostructured thin film on (a) bare glass and (b) 5, (c) 10, and (d) $15 \mathrm{~nm}$ of Au catalyst layer.

by other researches using sputtering deposition $[14,15]$ but with different surface morphology.

3.1.1. EDX Spectra. The EDX characterization was done to further study the material components of the AZO samples. Although the weight percentage (wt\%) values shown in figures may not be taken as absolute values, relative comparison can be made between the samples. The EDX results for $\mathrm{AZO}$ nanorods thin films grown on 5, 10, and $15 \mathrm{~nm}$ shown in Figures 4(a), 4(b), and 4(c) confirmed that the films contain aluminium (Al), zinc $(\mathrm{Zn})$, and oxygen $\left(\mathrm{O}_{2}\right)$ elements. Carbon $(\mathrm{C})$ peak observed from the sample on $5 \mathrm{~nm}$ Au may form contamination in the environment. We expected Au peak from the spectra but no Au peak was observed; thus the growth mechanism of the individual nanorods on the surface may be different from the vapourliquid-solid (VLS) growth $[16,17]$.

3.1.2. Crystalline Quality. XRD patterns of the AZO nanorods thin films on 5 and $10 \mathrm{~nm}$ thicknesses of Au catalyst are shown in Figure 5. From the figure, it can be seen that both samples showed a major peak at $34.4^{\circ}$ without any impurity phase found. This peak indicates the $\mathrm{ZnO}$ (002) wurtzite hexagonal peak $[18,19]$. The XRD patterns do not show significant difference between the two samples.

Figure 6 shows the Raman spectra of AZO nanostructured on 5, 10, and $15 \mathrm{~nm} \mathrm{Au}$ catalyst at the range of
$100-1000 \mathrm{~cm}^{-1}$. From the figure, there are 3 similar peaks occurring for all samples at 437.58, 577.35, and $756.49 \mathrm{~cm}^{-1}$. The peak at $437.58 \mathrm{~cm}^{-1}$ is assigned as optical phonon $\mathrm{E}_{2}$ that corresponds to the wurtzite hexagonal phase of $\mathrm{ZnO}$. This peak supports the XRD result that shows the crystalline quality at (002) which belongs to $\mathrm{ZnO}$ wurtzite hexagonal structure. The dominated peak at $577.35 \mathrm{~cm}^{-1}$ is attributed as $E_{1 L}$ was also observed for all samples. This appearance of $E_{1 L}$ mode is supposed to be due to the structural defects. The appearance of another peak at $756.49 \mathrm{~cm}^{-1}$ is attributed to local vibration of $\mathrm{Al}$ ion in $\mathrm{ZnO}$ lattice as a substitution of $\mathrm{Al}$ into $\mathrm{Zn}$ position.

3.2. Effect of Deposition Temperature. Figures 7(a), 7(b), 7(c), and $7(\mathrm{~d})$ show the AZO thin films deposited at 200, 300, 400 , and $500^{\circ} \mathrm{C}$, respectively. From Figures $7(\mathrm{a}), 7(\mathrm{c})$, and $7(d)$, it can be seen that the AZO thin films grown at 200, 400 , and $500^{\circ} \mathrm{C}$ are dense without any growth of nanorods observed, while a random AZO nanorods growth can be observed on AZO thin film deposited at $300^{\circ} \mathrm{C}$. Increasing the deposition temperature from 200 to 500 caused the deposition rate of AZO thin films to increase from 16.5 to $22.1 \mathrm{~nm} / \mathrm{min}$. This increase of AZO thin films deposition rate is due to the particles gaining the higher energy as the deposition temperature increased. Theoretically, the growth of AZO nanorods is depending on the substrate temperature. Therefore, we hypothesize that, at $200^{\circ} \mathrm{C}$, the deposition 


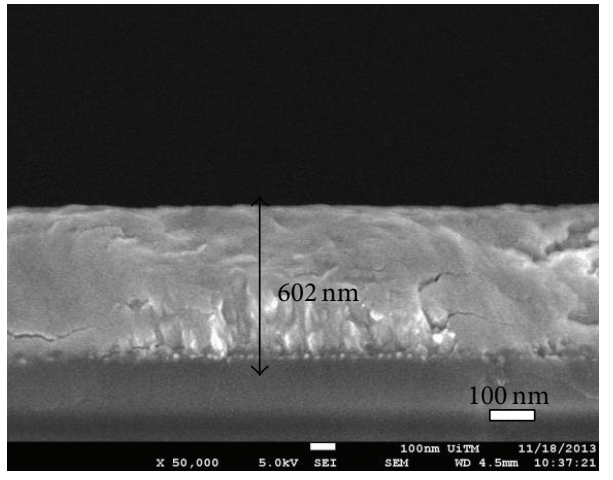

(a)

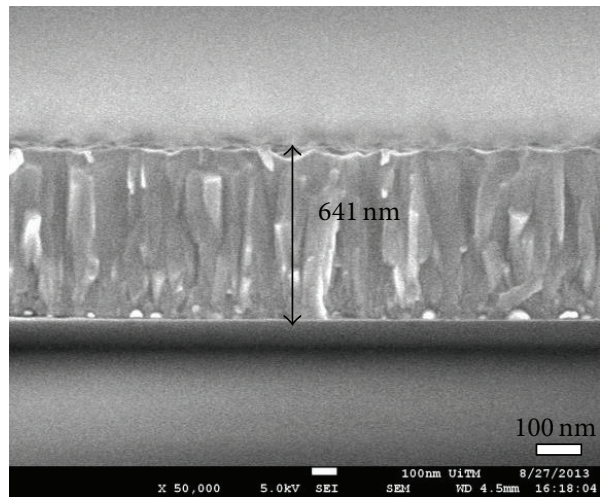

(c)

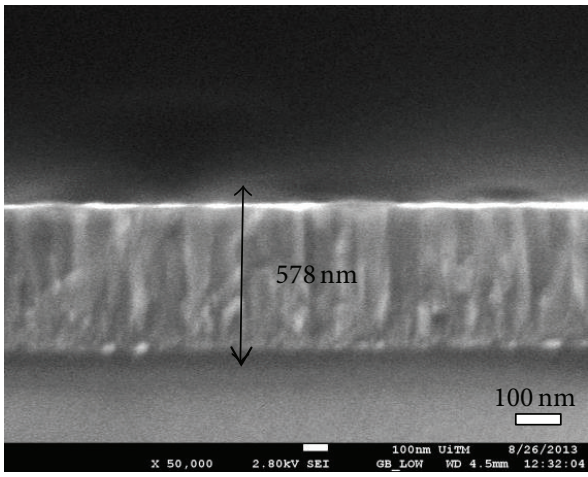

(b)

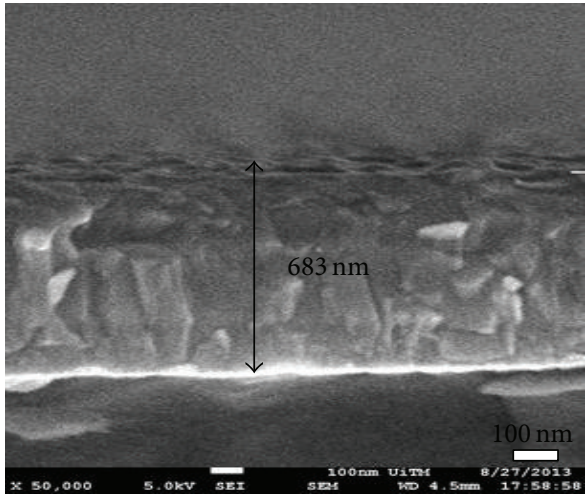

(d)

FIGURE 3: FESEM cross-section morphology of AZO nanostructured thin film on (a) bare glass and (b) 5, (c) 10, and (d) $15 \mathrm{~nm}$ of Au catalyst layer.

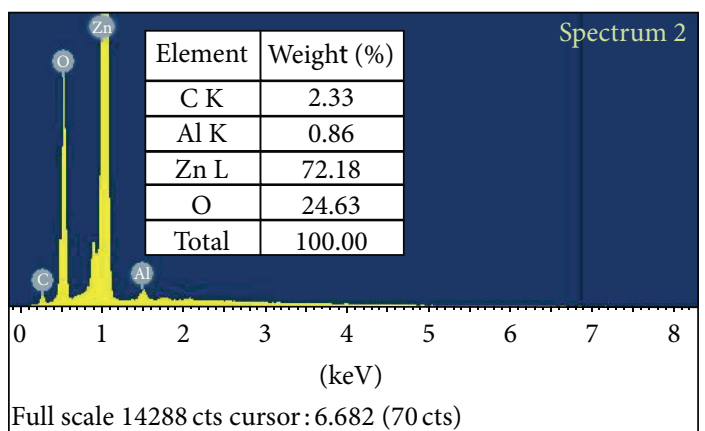

(a)

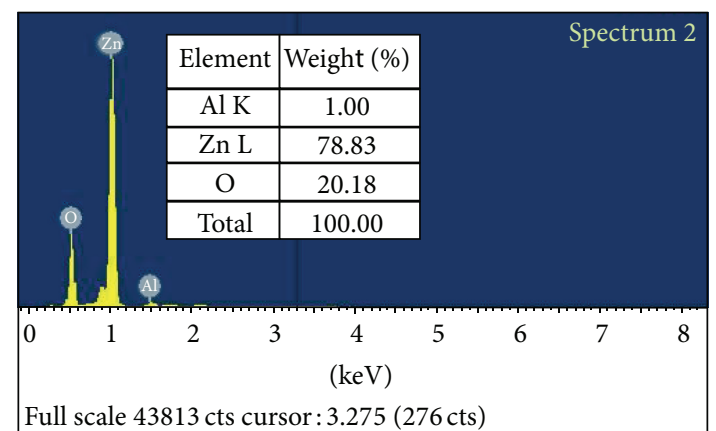

(b)

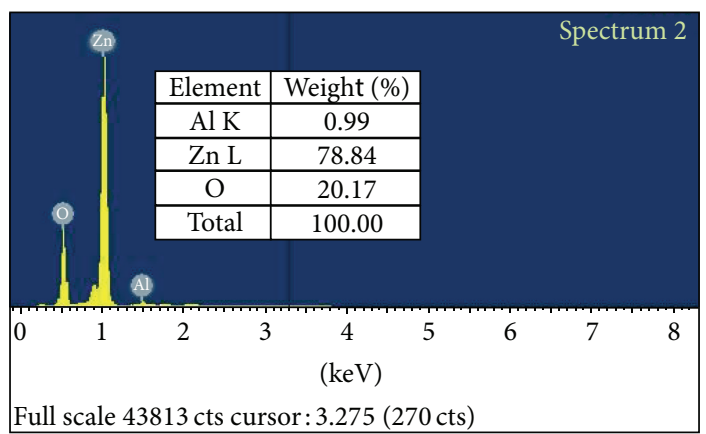

(c)

Figure 4: AZO EDX spectra on (a) $5 \mathrm{~nm}$, (b) $10 \mathrm{~nm}$, and (c) $15 \mathrm{~nm}$ of Au catalyst. 


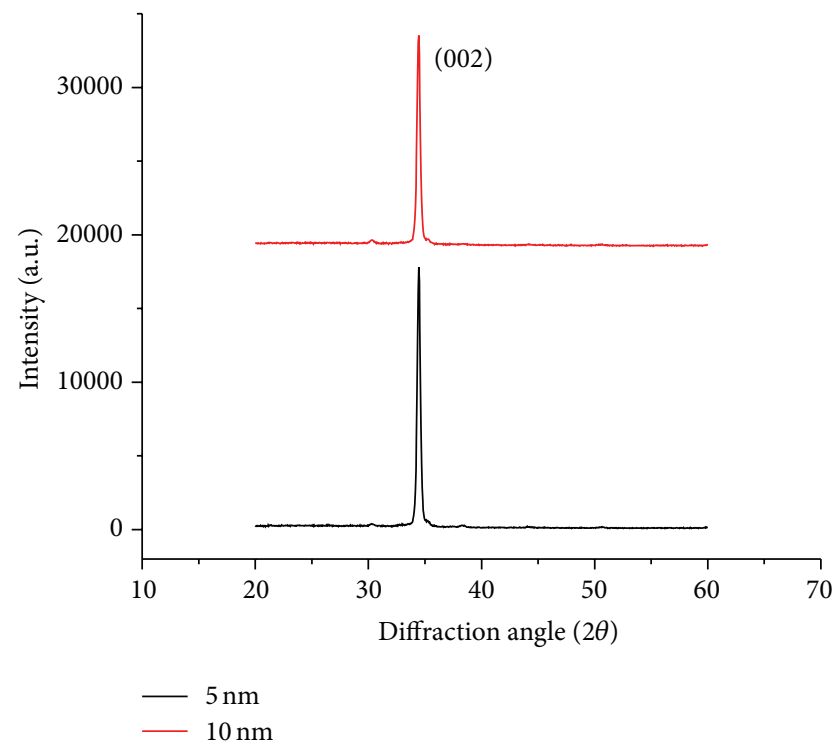

FIGURE 5: XRD pattern of AZO thin films prepared at different $\mathrm{Au}$ catalyst thickness.

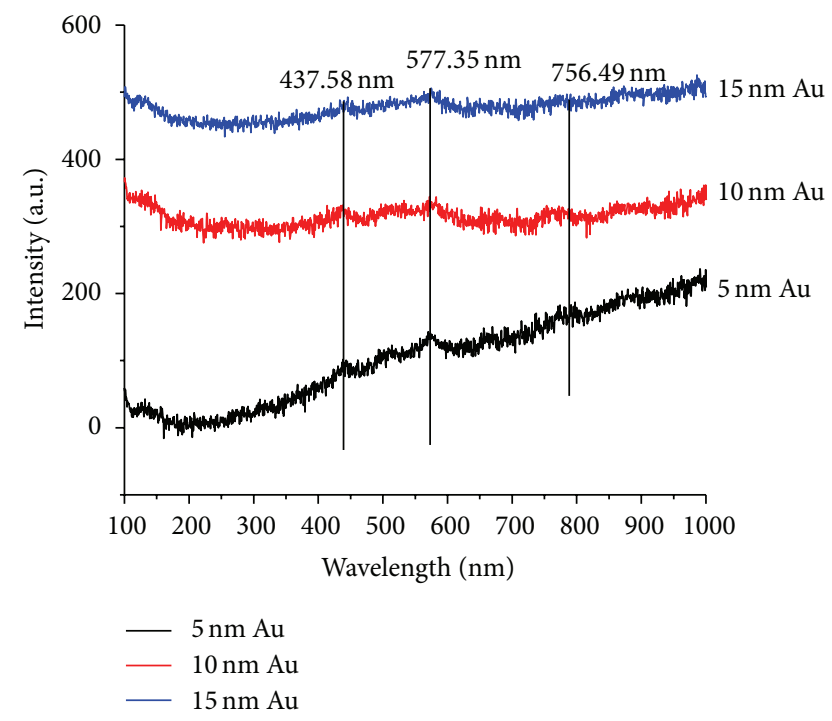

FIGURE 6: Raman spectra of AZO nanostructured on (a) 5, (b) 10, and (c) $15 \mathrm{~nm}$ of Au catalyst.

heat delivers sufficient energy for the particles to band together on the surface while for the 400 and $500^{\circ} \mathrm{C}$ samples deposition rate is too much and the formation of dense thin films is more than formation of AZO nanorods. We assume that, at $300^{\circ} \mathrm{C}$, the atoms have enough energy to form the nanorods structured. The inset shows the cross-section for the respective sample. As can be seen in Figure 7, the columnar structure can only be seen for the $300^{\circ} \mathrm{C}$ sample.

3.2.1. Crystalline Quality. The XRD patterns of the AZO thin films with regards to temperature changes are shown in Figure 8. All samples showed a major peak at around 34.4 $34.5^{\circ}$ without any impurity phase found. With increasing
TABLE 1: Crystallite size for different substrate temperature.

\begin{tabular}{lccc}
\hline $\begin{array}{l}\text { Substrate } \\
\text { temperature }\left({ }^{\circ} \mathrm{C}\right)\end{array}$ & $\begin{array}{c}\text { Crystallite } \\
\text { size }(\mathrm{nm})\end{array}$ & $\begin{array}{c}\text { FHWM } \\
\text { (degrees) }\end{array}$ & $2 \theta$ \\
\hline 200 & 0.50 & 0.35 & 34.41 \\
300 & 0.52 & 0.34 & 34.44 \\
400 & 0.53 & 0.33 & 34.46 \\
500 & 0.57 & 0.31 & 34.48 \\
\hline
\end{tabular}

temperature from 200 to $500^{\circ} \mathrm{C}$, the angle of measured diffraction peaks does not change significantly; however, the intensities of these peaks become more intense and sharper when the substrate temperature is increased from 200 to $400^{\circ} \mathrm{C}$. Ma et al. reported that this may happen because the crystallinity of the AZO sample is improved and crystallite sizes become larger when the substrate temperature is increased [20]. The intensity began to decrease as the deposition temperature increased to $500^{\circ} \mathrm{C}$. This implies that the crystalline quality increased with the temperature which is acceptable since the higher deposition temperature supplies sufficient energy to the arriving atoms and molecules to arrange themselves to form a uniform crystal orientation. However further increasing the temperature might induce the transition of crystal orientation and thus deteriorate the crystalline quality [21].

Table 1 shows the crystallite size for each sample at different substrate temperature. From Table 1, it can be seen that the crystallite size was increased from 0.50 to $0.57 \mathrm{~nm}$ when the substrate temperature was increased from 200 to $500^{\circ} \mathrm{C}$. It is in accordance with the fact that the deposited particles get more energy to migrate into the lattice position. This crystallite size was calculated by using Scherrer equation [22]. Consider

$$
D=\frac{0.94 \lambda}{\beta \cos \theta}
$$

where $D$ is the crystallite size, 0.94 is the constant, and $\lambda$ is the wavelength of X-ray which used copper $(\mathrm{Cu})$ source. Then $\beta$ is the FWHM and $\theta$ is the diffraction angle where the peaks are observed from XRD.

\section{Conclusion}

AZO nanorod thin films were deposited by sputtering method on Au catalyst layers. The effects of the Au catalyst layers thickness and also the deposition temperature on the physical morphologies of the AZO nanorod thin films were studied. AZO thin films having distinct columnar structures were deposited and individual nanorods were observed on the surface of the AZO thin films deposited on the Au catalyst. This phenomenon was not observed for the AZO thin film deposited on bare glass, which confirmed the role of the $\mathrm{Au}$ catalyst on the formation of the columnar nanorods. Besides the Au catalyst layer, the AZO deposition temperature also influenced the morphology of the film and also the thin film crystallite size. The AZO nanorods thin films with individual nanorods on the surface were grown on a $5 \mathrm{~nm}$ 


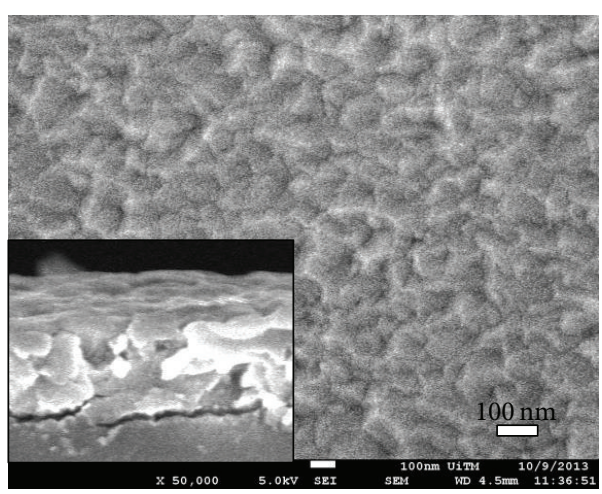

(a)

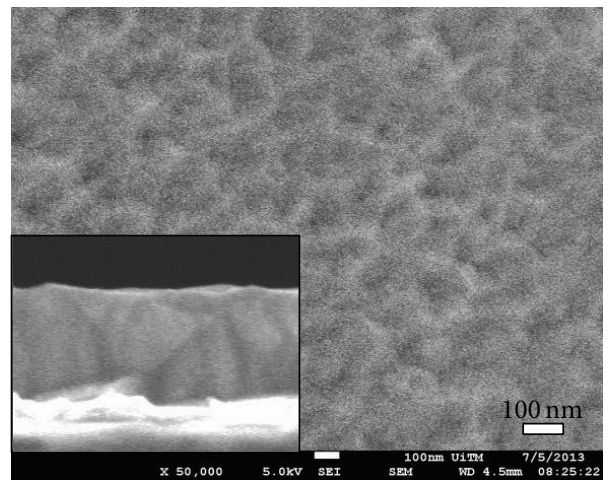

(c)

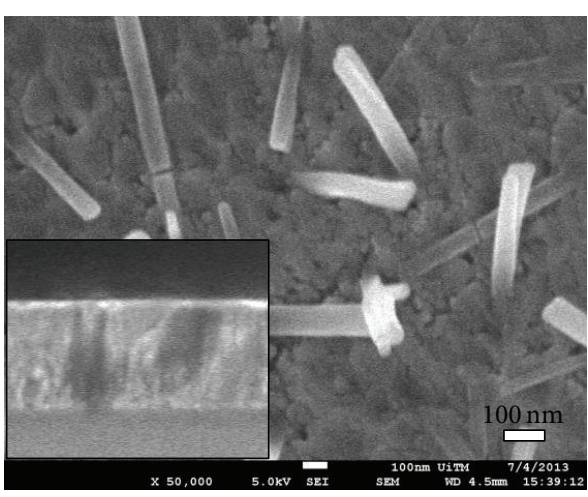

(b)

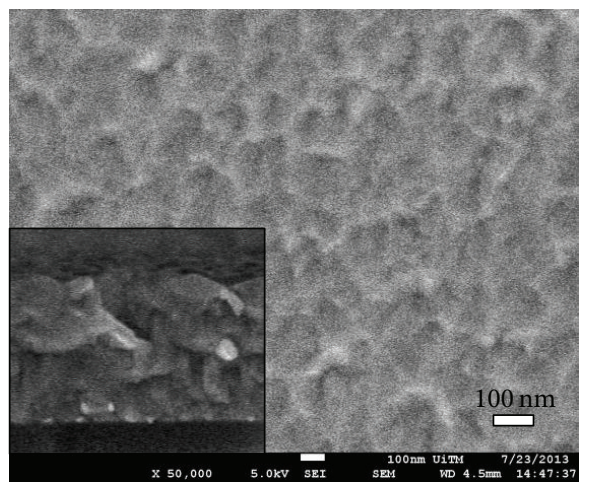

(d)

Figure 7: FESEM images of AZO thin film on constant Au catalyst thickness (5 nm) at (a) 200, (b) 300 , (c) 400, and (d) $500^{\circ} \mathrm{C}$. Inset shows the cross-section images for respective samples.

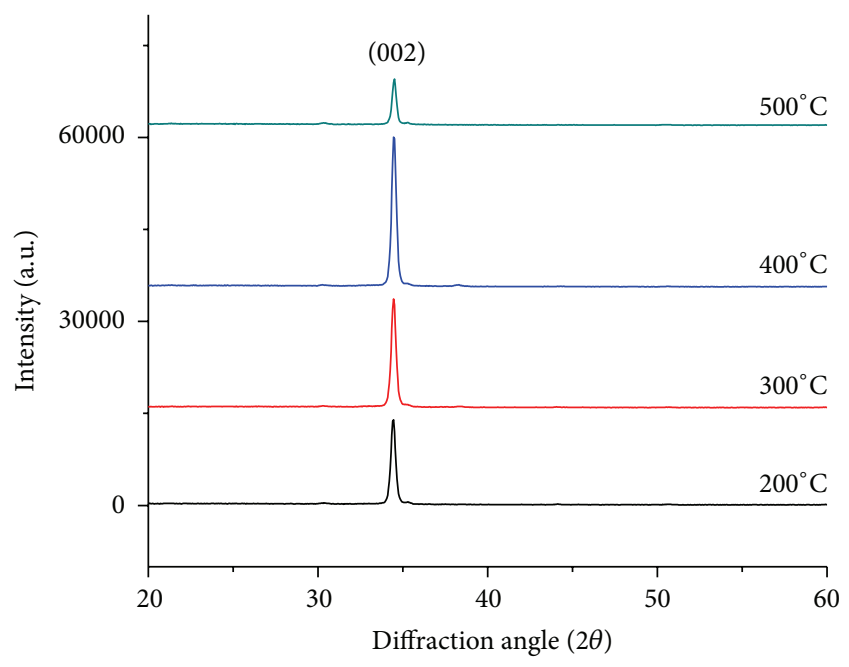

FIGURE 8: XRD patterns of AZO thin films prepared at different substrate temperature.

thick Au catalyst layer at deposition temperature of $300^{\circ} \mathrm{C}$. The deposited AZO thin films exhibit crystalline structure with wurtzite hexagonal orientation as confirmed from the XRD results.

\section{Conflict of Interests}

The authors declare that there is no conflict of interests regarding the publication of this paper.

\section{Acknowledgments}

This work is partially supported by the Ministry of Higher Education Malaysia under the Science Fund Grant (Project Code: 100-RMI/SF 16/6/2 (15/2013) (MOSTI-06-01-01SF0662)) and the Research Management Institute of UiTM for the supporting Grant (600-RMI/DANA 5/3/CIFI $(115 / 2013))$.

\section{References}

[1] Y. S. Park, M. Seo, J. Yi, D. Lim, and J. Lee, "Characteristics of aluminum-doped zinc oxide films with oxygen plasma treatment for solar cell applications," Thin Solid Films, vol. 547, pp. 47-51, 2013.

[2] Z. B. Ayadi, L. El Mir, K. Djessas, and S. Alaya, "The properties of aluminum-doped zinc oxide thin films prepared by rfmagnetron sputtering from nanopowder targets," Materials Science and Engineering C, vol. 28, no. 5-6, pp. 613-617, 2008.

[3] S. H. Jeong, J. W. Lee, S. B. Lee, and J. H. Boo, "Deposition of aluminum-doped zinc oxide films by RF magnetron sputtering and study of their structural, electrical and optical properties," Thin Solid Films, vol. 435, no. 1-2, pp. 78-82, 2003. 
[4] N. Evcimen Duygulu, A. O. Kodolbas, and A. Ekerim, "Effects of argon pressure and r.f. power on magnetron sputtered aluminum doped $\mathrm{ZnO}$ thin films," Journal of Crystal Growth, vol. 394, pp. 116-125, 2014.

[5] J. Sengupta, R. K. Sahoo, and C. D. Mukherjee, "Effect of annealing on the structural, topographical and optical properties of sol-gel derived $\mathrm{ZnO}$ and AZO thin films," Materials Letters, vol. 83, pp. 84-87, 2012.

[6] T. B. Asafa, N. Tabet, and S. A. M. Said, "Taguchi methodANN integration for predictive model of intrinsic stress in hydrogenated amorphous silicon film deposited by plasma enhanced chemical vapour deposition," Neurocomputing, vol. 106, pp. 86-94, 2013.

[7] D. K. Kim and H. B. Kim, "Room temperature deposition of $\mathrm{Al}$-doped $\mathrm{ZnO}$ thin films on glass by RF magnetron sputtering under different Ar gas pressure," Journal of Alloys and Compounds, vol. 509, no. 2, pp. 421-425, 2011.

[8] P. Sundara Venkatesh, C. L. Dong, C. L. Chen, W. F. Pong, K. Asokan, and K. Jeganathan, "Local electronic structure of $\mathrm{ZnO}$ nanorods grown by radio frequency magnetron sputtering," Materials Letters, vol. 116, pp. 206-208, 2014.

[9] K. W. Johnson, S. Guruvenket, R. A. Sailer, S. P. Ahrenkiel, and D. L. Schulz, "Atmospheric pressure plasma enhanced chemical vapor deposition of zinc oxide and aluminum zinc oxide," Thin Solid Films, vol. 548, pp. 210-219, 2013.

[10] X. J. Qin, L. Zhao, G. J. Shao, and N. Wang, "Influence of solvents on deposition mechanism of Al-doped $\mathrm{ZnO}$ films synthesized by cold wall aerosol-assisted chemical vapor deposition," Thin Solid Films, vol. 542, pp. 144-149, 2013.

[11] A. Illiberi, P. J. P. M. Simons, B. Kniknie et al., "Growth of ZnOx:Al by high-throughput CVD at atmospheric pressure," Journal of Crystal Growth, vol. 347, no. 1, pp. 56-61, 2012.

[12] P. Zhang, R. Y. Hong, Q. Chen, and W. G. Feng, "On the electrical conductivity and photocatalytic activity of aluminumdoped zinc oxide," Powder Technology, vol. 253, pp. 360-367, 2014.

[13] S. H. H. Z. Aznilinda, A. B. Raudah, W. F. H. Abdullah, and M. Rusop, "Substrate temperature dependence on sputtered titania thin film," Advanced Materials Research, vol. 795, pp. 294-298, 2013.

[14] Y. Zhou, P. J. Kelly, A. Postill, O. Abu-Zeid, and A. A. Alnajjar, "The characteristics of aluminium-doped zinc oxide films prepared by pulsed magnetron sputtering from powder targets," Thin Solid Films, vol. 447-448, pp. 33-39, 2004.

[15] N. Neves, R. Barros, E. Antunes et al., "Aluminum doped zinc oxide sputtering targets obtained from nanostructured powders: processing and application," Journal of the European Ceramic Society, vol. 32, no. 16, pp. 4381-4391, 2012.

[16] S. R. Hejazi, H. R. M. Hosseini, and M. S. Ghamsari, "The role of reactants and droplet interfaces on nucleation and growth of $\mathrm{ZnO}$ nanorods synthesized by vapor-liquid-solid (VLS) mechanism," Journal of Alloys and Compounds, vol. 455, no. 1-2, pp. 353-357, 2008.

[17] H. Yumoto, T. Sako, Y. Gotoh, K. Nishiyama, and T. Kaneko, "Growth mechanism of vapor-liquid-solid (VLS) grown indium tin oxide (ITO) whiskers along the substrate," Journal of Crystal Growth, vol. 203, no. 1, pp. 136-140, 1999.

[18] M. Jlassi, I. Sta, M. Hajji, and H. Ezzaouia, "Effect of nickel doping on physical properties of zinc oxide thin films prepared by the spray pyrolysis method," Applied Surface Science, vol. 301, pp. 216-224, 2014.
[19] Z. Ben Ayadi, H. Mahdhi, K. Djessas, J. L. Gauffier, L. El Mir, and S. Alaya, "Sputtered Al-doped $\mathrm{ZnO}$ transparent conducting thin films suitable for silicon solar cells," Thin Solid Films, vol. 553, pp. 123-126, 2014.

[20] J. Ma, F. Ji, H.-L. Ma, and S.-Y. Li, "Preparation and properties of transparent conducting zinc oxide and aluminum-doped zinc oxide films prepared by evaporating method," Solar Energy Materials and Solar Cells, vol. 60, no. 4, pp. 341-348, 2000.

[21] S. Hana, K. Nishioka, and S. Horita, "Enhancement of the crystalline quality of reactively sputtered yttria-stabilized zirconia by oxidation of the metallic target surface," Thin Solid Films, vol. 517, no. 20, pp. 5830-5836, 2009.

[22] D.-H. Cho, Y.-D. Chung, K.-S. Lee et al., "Influence of growth temperature of transparent conducting oxide layer on $\mathrm{Cu}(\mathrm{In}, \mathrm{Ga})$ Se 2 thin-film solar cells," Thin Solid Films, vol. 520, no. 6, pp. 2115-2118, 2012. 

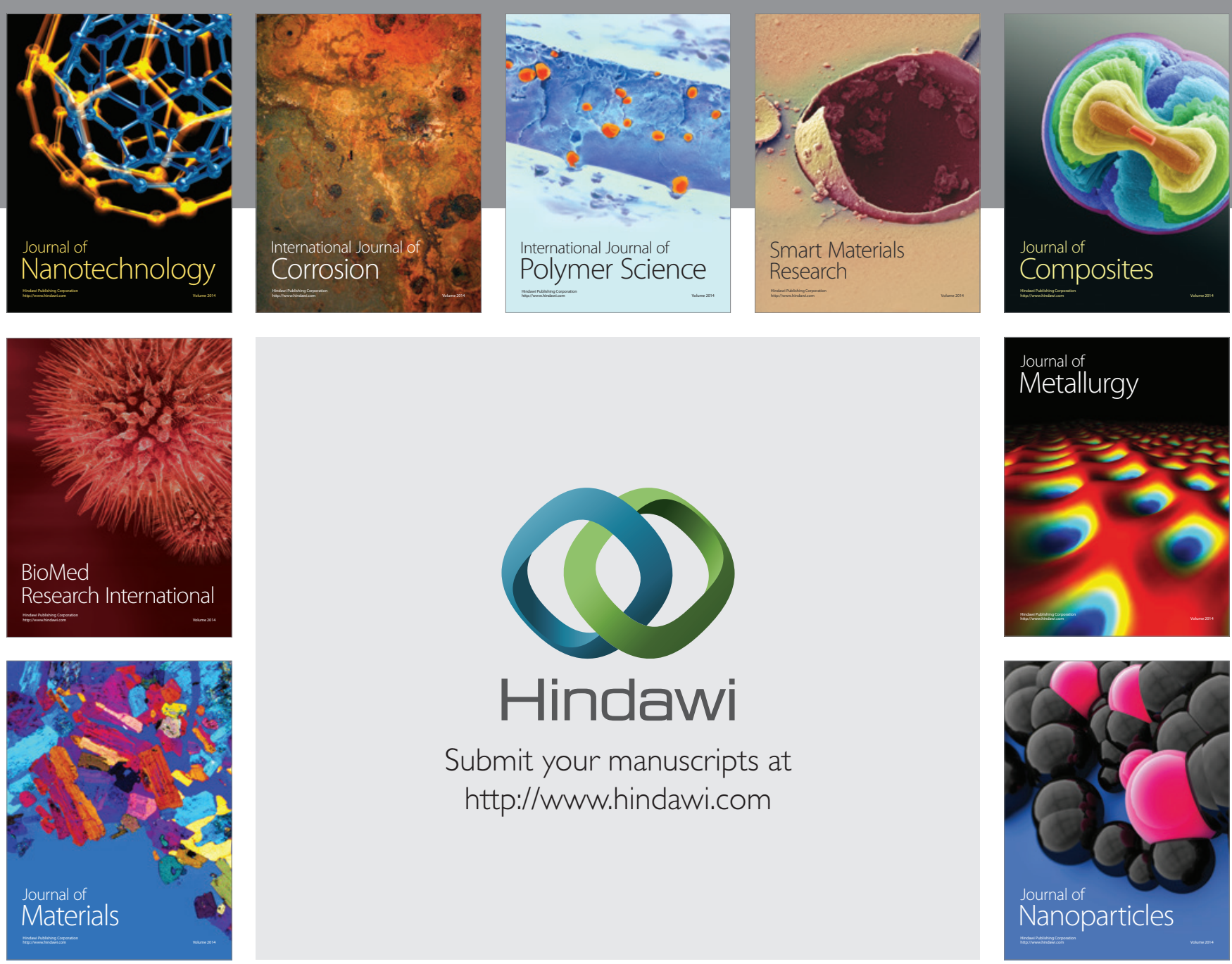

Submit your manuscripts at http://www.hindawi.com
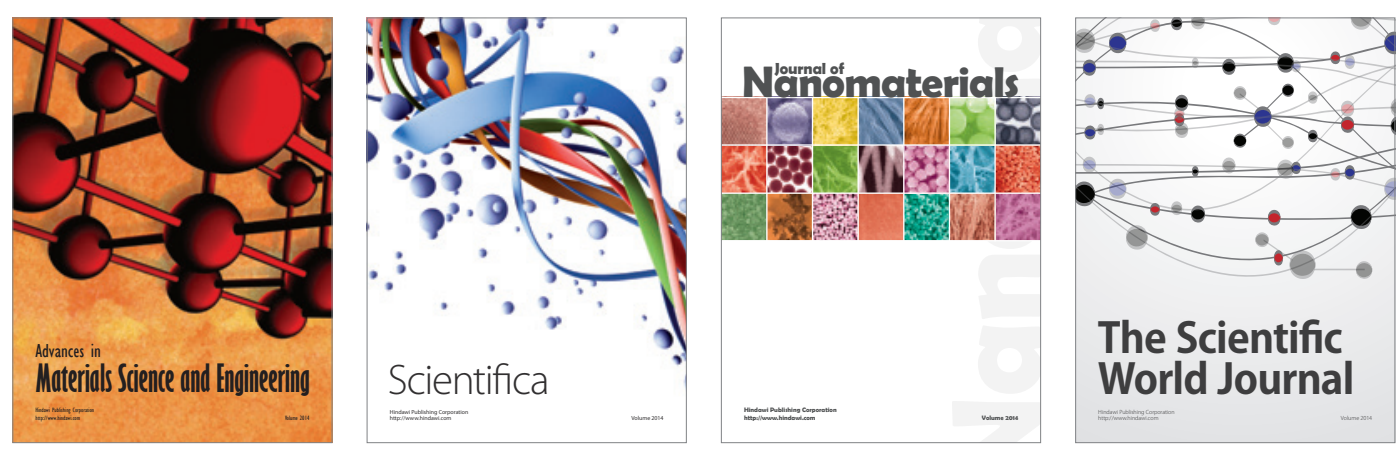

\section{The Scientific World Journal}
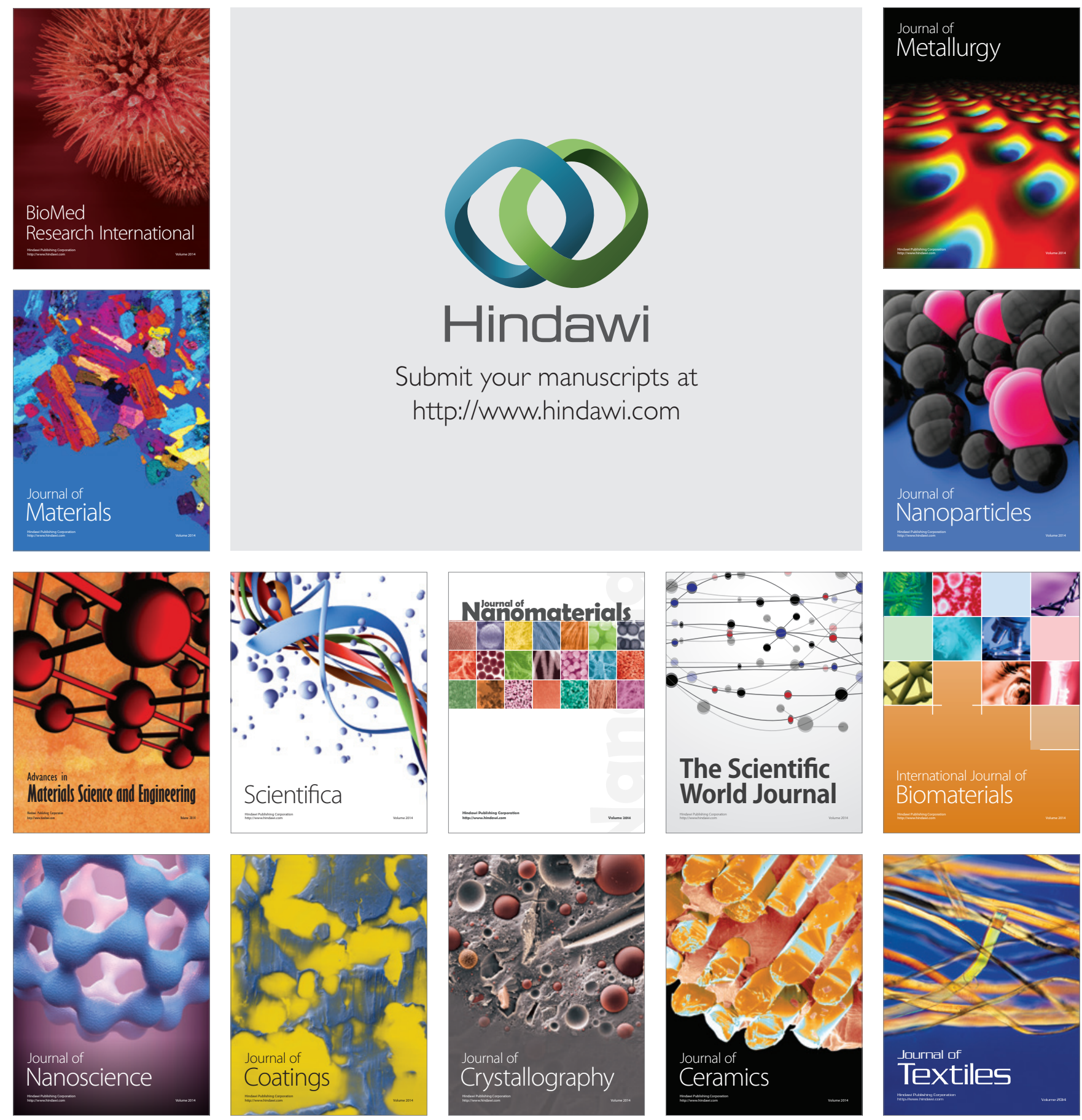